\title{
Research Paper \\ Comparing the Effects of Aloe Vera Leaf Extract On K562 Tumor Cell and Periph- eral Blood Mononuclear Cells
}

\author{
Minoo Shaddel ${ }^{1}\left({ }^{\circ},{ }^{*}\right.$ Hamid Shamsi $^{1,2}\left(\mathbb{1}\right.$, Payman Tavakoli ${ }^{2}$, Seyyed Meysam Abtahi Foroushani², Roya Shamsi ${ }^{3}$
}

1. Department of Parasitology and Mycology, School of Medicine, AJA University of Medical Sciences, Tehran, Iran

2. Department of Microbiology, Faculty of Veterinary medicine, Urmia University, Urmia, Iran.

3. Department of Clinical Nutrition and Dietetics, School of Nutrition Sciences and Food Technology, Shahid Beheshti University of Medical Sciences, Tehran, Iran

\begin{tabular}{|c|c|}
\hline $\begin{array}{l}\text { Use your device to scan } \\
\text { and read the article online }\end{array}$ & Chat on Shaddel M, Shamsi H, Tavakoli P, Abtahi Foroushani SM, Shamsi R. [The Effects of Aloe Vera Leaf Extract on the K562 \\
\hline 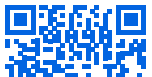 & $\begin{array}{l}\text { Human Tumor Cell Line and PBMC Cells (Persian)]. Quarterly of "The Horizon of Medical Sciences". 2019; 25(3):216-229. https:// } \\
\text { doi.org/10.32598/hms.25.3.216 }\end{array}$ \\
\hline 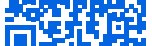 & doil'https://doi.org/10.32598/hms.25.3.216 \\
\hline
\end{tabular}

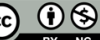

Received: 16 Oct 2018 Accepted: 09 Apr 2019 Available Online: $01 \mathrm{Jul} 2019$

Key words: Aloe Vera leaf extract K562, MTT

\section{A B STRACT}

Aims Aloe Vera is among the crucial medicinal plants, with proven anti-cancer effects. This study aimed to investigate the effect of plant extracts of Aloe Vera Leaf (AVL) on the proliferation of cell lines K562 (erythroleukemia) and Peripheral Blood Mononuclear Cells (PBMCs).

Methods \& Materials The inner parts of the plant, including the gelatinous substance, were emptied, and the outer layer was used to prepare the lyophilized extract. The extract was dissolved in DMSO. K562 cells and PBMCs were cultured with 9.375, 18.75, 37.5, 75, 150, and $300 \mu \mathrm{g} / \mathrm{mL}$ concentrations of AVL for 24, 48 , or 72 hours. After cultivation, the IC50 was determined for the K562 and normal PBMCs, using the MTT assay (4,5-dimethylthiazol-2-yl)-2,5-diphenyl tetrazolium bromide). Doxorubicin was used as a positive control.

Findings The obtained data suggested that the viability of cells in both the leukemic cell line and normal PBMCs significantly decreased by the treatment with the extract in a dose-dependent manner; however, the AVL toxicity for PBMC was significantly more than K562. IC50 for the standard drug was also significantly less than AVL extract.

Conclusion AVL possesses cytotoxic effects for K562 and PBMCs. Nevertheless, it has no selective benefits and has more cytotoxic effects on PBMCs.

\section{Extended Abstract}

\section{Introduction}

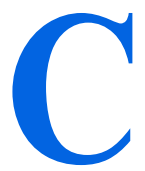

onsidering the susceptibility and treatment problems of malignant diseases, as well as their high treatment costs, this study was designed. We examined the traditional usage of Aloe Vera (AV) plant.
Winters et al. (1980) explored the effects of AV extracts on human tumor cells. They reported anti-tumor and protective effects of it on healthy human embryonic lung cells.

$\mathrm{AV}$ is among the most important species of medical plants. Many studies have reported the anti-tumor effect of its leaves. This study aimed to evaluate the effect of Aloe Vera Leaf(AVL) extract on the proliferation of K562 erythroleukemic cell lines and Peripheral Blood Mononuclear Cells (PBMCs)

\section{*Corresponding Author:}

Hamid Shamsi, DVM.

Address: Department of Microbiology, Faculty of Veterinary medicine, Urmia University, Urmia, Iran.

Tel: +98 (873)8720789

E-mail: Shamsi.hamid@gmail.com 


\section{Methods}

This experimental (descriptive-cross sectional) study was conducted using PBMCs, in the Faculty of Veterinary Medicine, Urmia University, in 2016. To isolate PBMCs, $15 \mathrm{~mL}$ of heparinized blood $(200 \mathrm{u} / \mathrm{mL})$ was obtained from 3 volunteers who were informed about the test (healthy, 25 years old, $75 \mathrm{~kg}$ ). The inner contents of the AV plant, including the gel, were drained and a lyophilized aqueous extract was prepared. The obtained extract was dissolved in DMSO. The AVL extract, at the concentrations of 9.375, $18.75,37.5,75,150$, and $300 \mu \mathrm{g} / \mathrm{mL}$, was exposed to $\mathrm{K} 562$ cells and PBMCs at 24, 48, and 72 hours after the treatment. After incubation, IC50 values in K562 cells and PBMCs were measured by the MTT assay. Doxorubicin, as a positive control.

\section{Results}

The obtained data suggested a decrease in the viability of K562 cells and normal PBMCs after the treatment with the extract, as a concentration-dependent method. However, the toxicity of AVL extract to PBMCs was significantly higher than that of the K562 cells. The IC50 for the standard drug was significantly lower than that of the AVL extract (Figure $1,2,3,4 \& 5)$.

\section{Discussion}

Chen et al. (2005) studied the inhibitory effect of Cyanidin (a major constituent of the AVL) on tumor cell growth and its induced apoptosis. Their results were consistent with those of the present study regarding cancer cell killing. Moreover, Yeh et al. (2009) investigated the effect of cytotoxic triterpenes (extracted from Antrodia camphorate) on some colon cancer cells, including HT-29, HCT-116, and SW-480. They reported the cytotoxic and apoptotic effects of this compound, which is in agreement with our results in terms of killing cancer cells; it indicates that triterpenes compounds have cancer-killing effects. Their study; however, revealed that triterpenes were not toxic to mam-

\section{K562-AVL-24,48 and 72h}

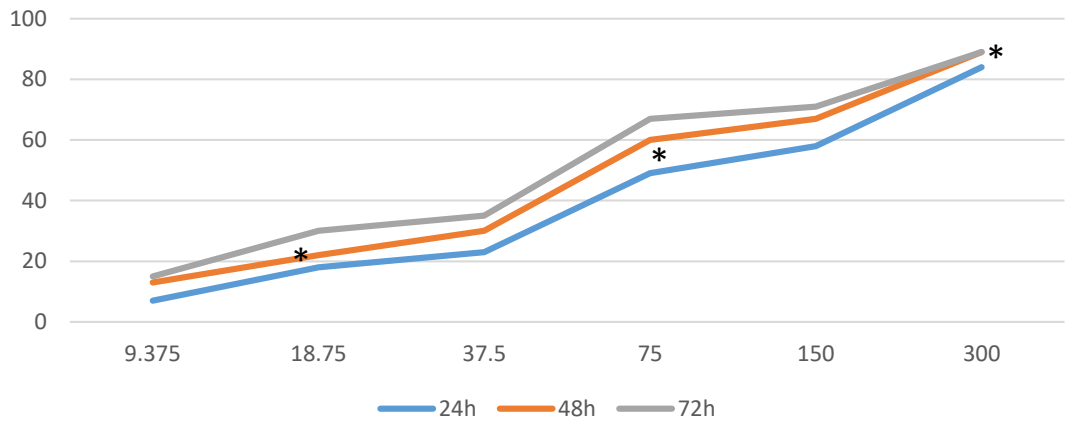

Quarterly of

The Horizon of Medical Sciences

Figure 1. Inhibitory effects on K562 cells at different concentrations $(\mu \mathrm{g} / \mathrm{mL})$ and 24,48 , and $72 \mathrm{~h}$ after exposure

*The significant difference level was set at $\mathrm{P}<0.05$

K562-AVL-24,48 and 72h

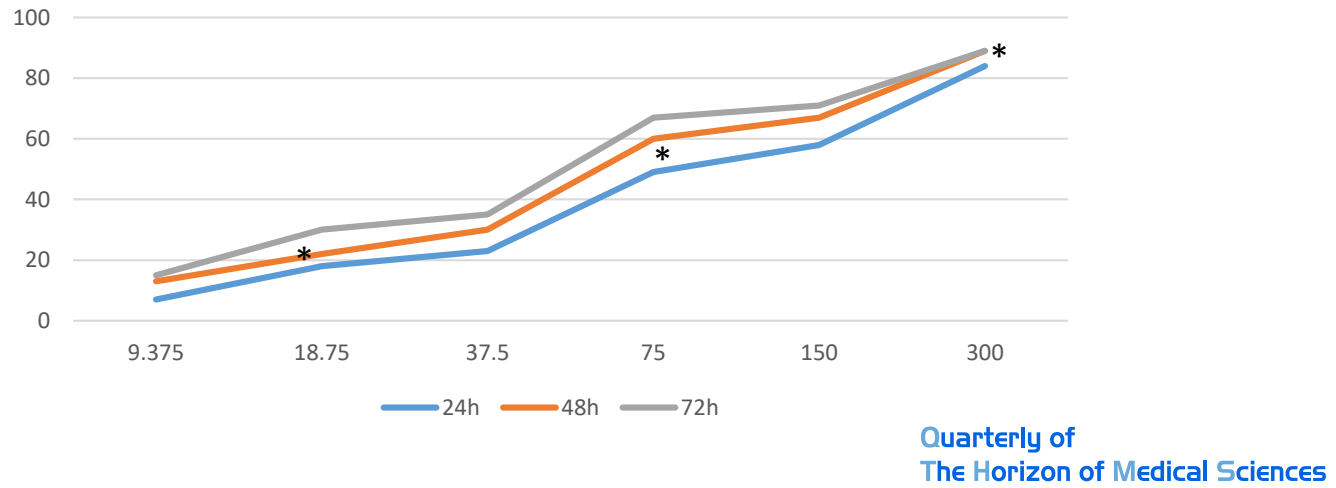

Figure 2. The inhibitory effect on PBMCs at different concentrations $(\mu \mathrm{g} / \mathrm{mL})$ and 24,48 , and $72 \mathrm{~h}$ after exposure

*The significant difference level was set at $\mathrm{P}<0.05$ 


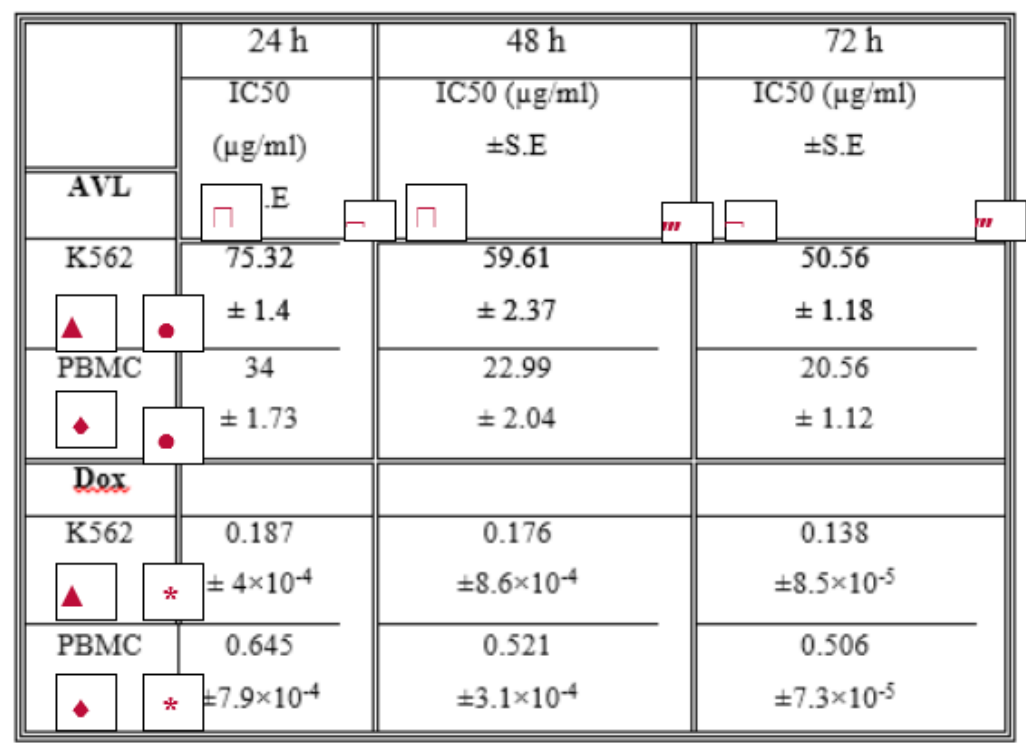

Figure 3. IC50 values in the control and intervention groups at 24, 48, and 72 hours

Quarterly of

The Horizon of Medical Sciences

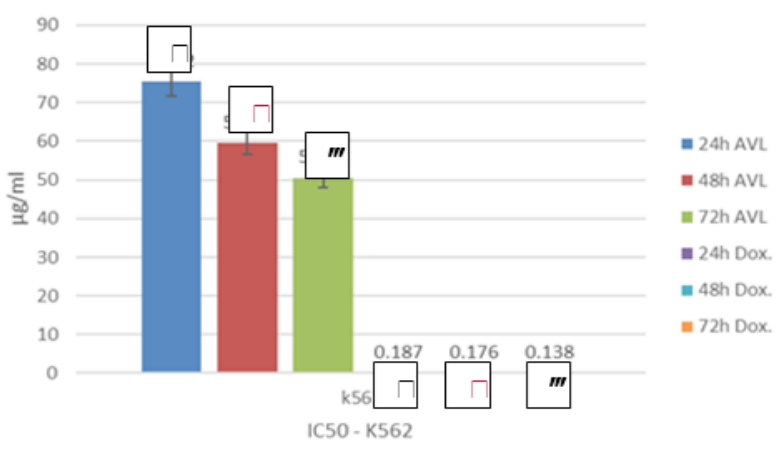

Quarterly of

The Horizon of Medical Sciences

Figure 4. Comparing IC50 effect in the control and intervention groups on K562 cells at 24, 48, and $72 \mathrm{~h}$ after exposure

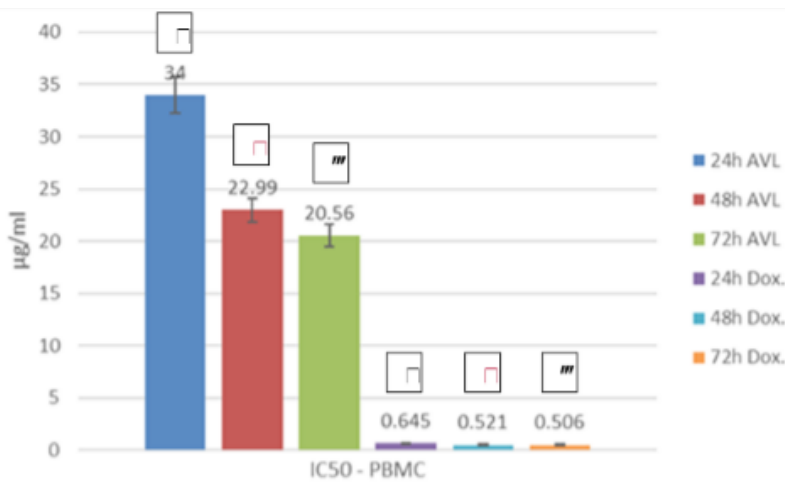

Figure 5. Comparing IC50 effect in the control and intervention groups on PBMCs at 24, 48, and $72 \mathrm{~h}$ after exposure 
mary epithelial (MCF10A) and primary foreskin fibroblast (HS68) cells.

It is recommended that the effects of each component of the AVL extract be studied separately, and the results be compared to determine which components have the most anti-cancer properties. Apart from the laboratory costs, there was no limitation conducting this study.

\section{Conclusion}

The AVL extract was toxic to K562 erythroleukemic cells and PBMCs; however, its toxicity was more significant in PBMCs. The standard drug doxorubicin effect revealed a significant difference between the IC50 of K562 cells and PBMCs; whereas its effect on K562 cells was four times higher.

\section{Ethical Considerations}

Compliance with ethical guidelines

All ethical principles were fully respected and necessary permissions were obtained.

\section{Funding}

This study received financial support from AJA University of Medical Sciences.

\section{Authors' contributions}

Minoo Shaddel and Hamid Shamsi each had a contribution rate of 35\%; Payman Tavakoli, Seyyed Meysam Abtahi Foroushani, and Roya Shamsi each had a contribution rate of $10 \%$.

\section{Conflicts of interest}

The authors declare no conflict of interest

\section{Acknowledgements}

The authors would like to thank laboratory officials at Urmia University and AJA University of Medical Sciences. 
This Page Intentionally Left Blank 


\title{
بررسى اثرات عصاره يوسته ألوئلدورا بر رده سلولى تومورى Ko7 و سلولهاى PBMC
}

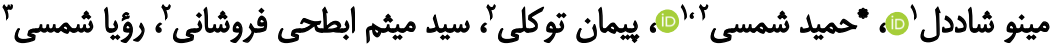

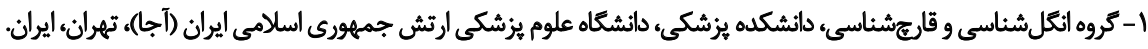

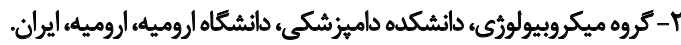

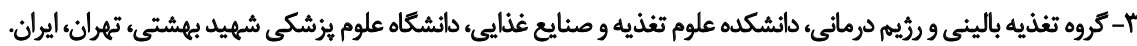

\begin{abstract}
QS

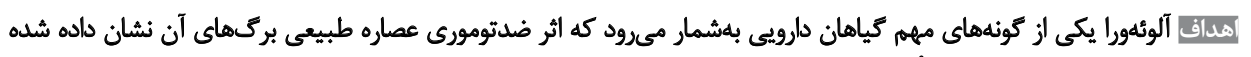

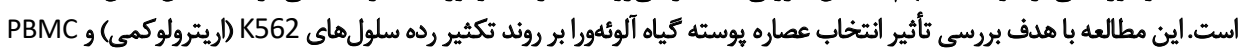

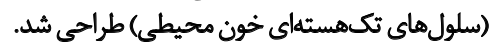

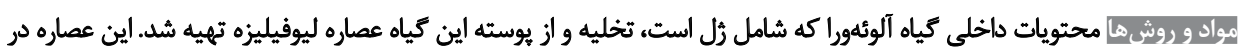

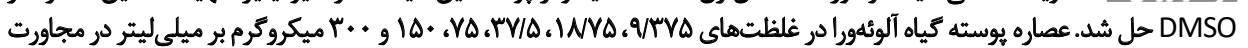

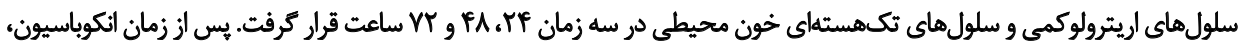

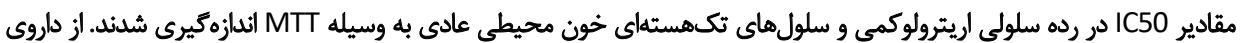

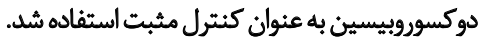

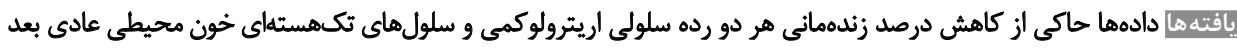

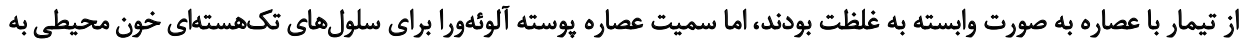

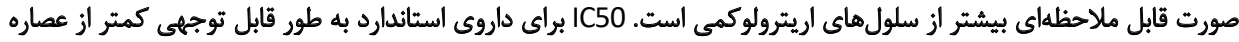
بوسته آلوثنورا بود.

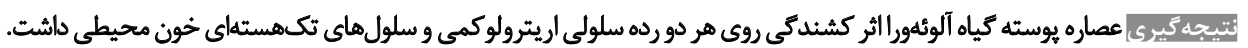

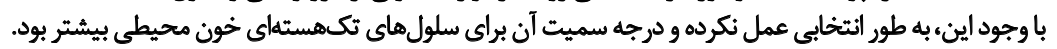

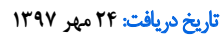

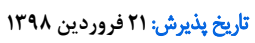

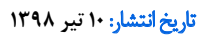

: looghlguls عصاره يوسته آلوئهورا، PBMC MTT 562K تست نست رده

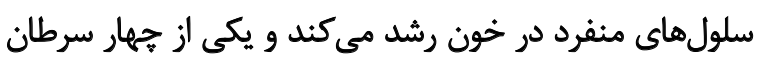

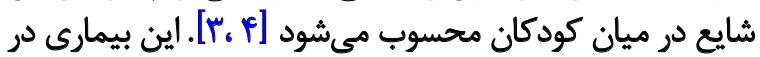

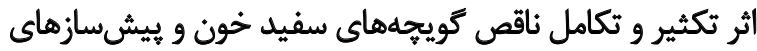

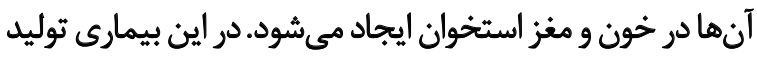

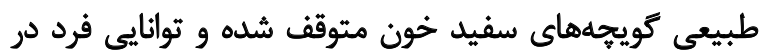

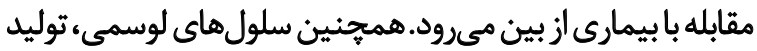

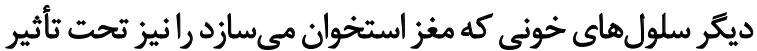

قرار مي دهند [f]

بسيارى از سرطانها در ابتدا به شيمى درمانى ياسخ مي دهنئ

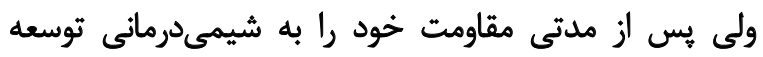

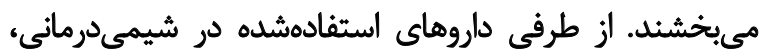

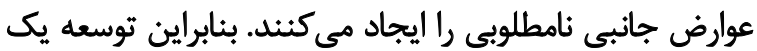

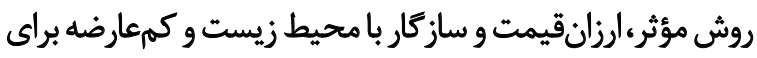

$$
\text { درمان سرطان ضرورى است. }
$$

doles

سرطان نهتنها يكى از شايعترين بيمارىها در سطح جهان

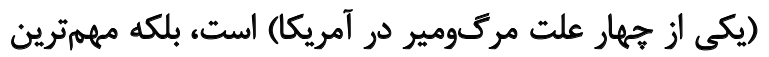

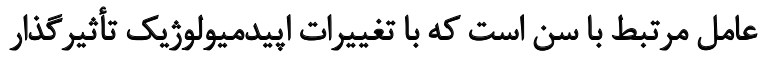

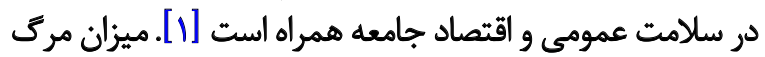

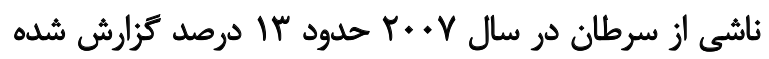

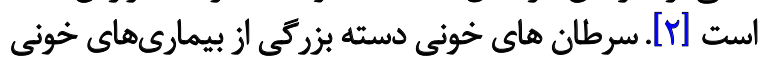

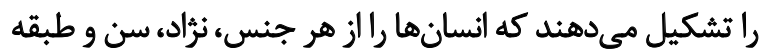

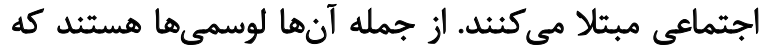

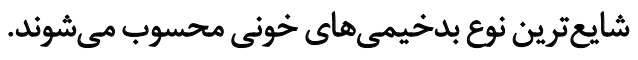

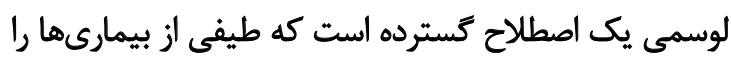

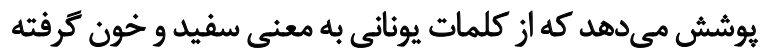
شده است. اين سرطان، كلاسى از ساركوماست كه به به صورت

* نويسئده مسئول:

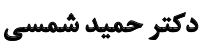

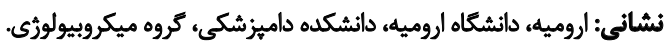

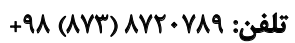
يست الكترونيكى: Shamsi.hamid@gmail.com 
g anthocyanidine، saponin، tannin، phenol، flavans

[q] proanthocyanidol

در سال •191 وينترز' و همكارانش، اثر ضدتومورى عصاره

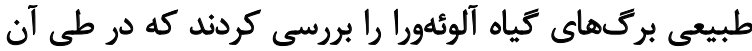

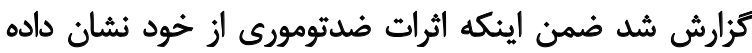

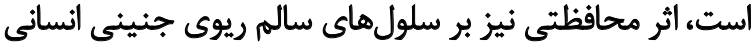
داشته است و اين در حالى استى است كه عصاره تجارى ائر اين كياه فاقد

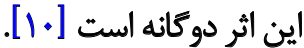

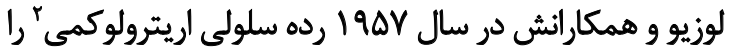

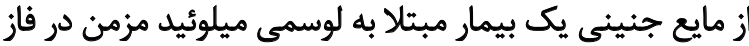

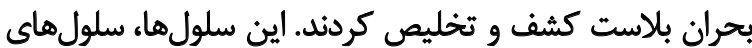

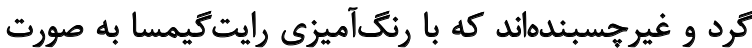

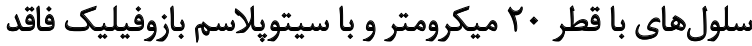

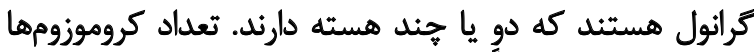

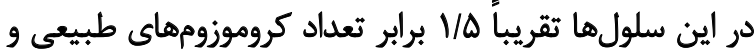

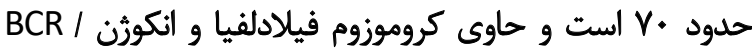
ABL

رده سلولى اريترولوكمى به عنوان مدل مناسبى براي مطالعات

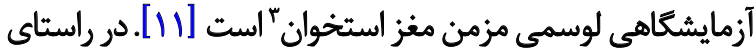

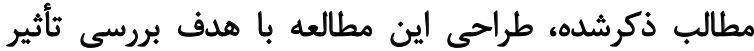

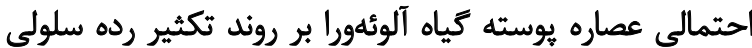
اريترولوكمى و سلولهاي تكهستهاي خون محيطى بـ انجام شد.

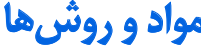

بركَهاي بزرى و ثازه اين كياه بس از تهيه از مراكز فروش

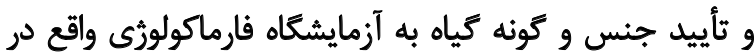

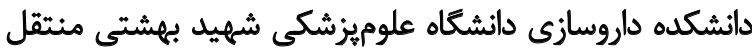

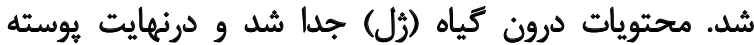

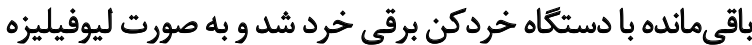

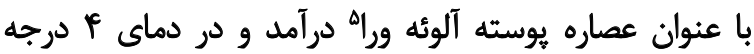
سانتى كراد نتخهدارى شد.

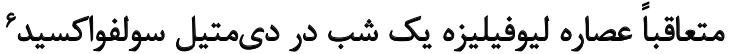

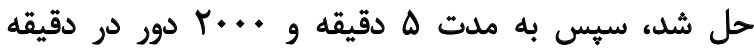

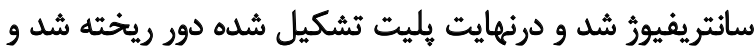

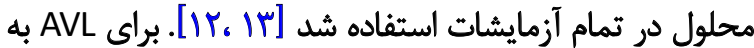

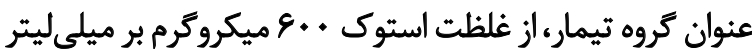

1. Winters

2. K562

3. Chronic Myeloid Leukemia (CML)

4. Peripheral Blood Mononuclear Cell (PBMC)

5. Aloe Vera Leaf Extract (AVL)

6. Dimethyl Sulfixide (DMSO)
استفاده از كياهان دارويى و تركيبات كياهي جديد از جمله

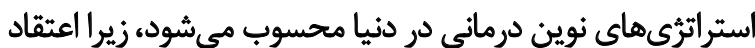

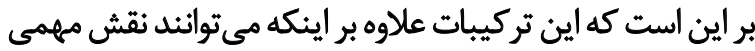

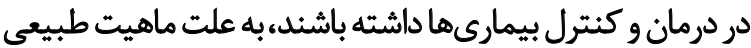

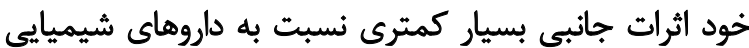
دارند [هات.

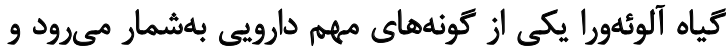

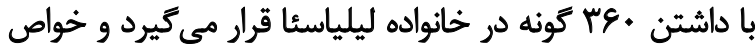

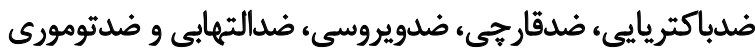

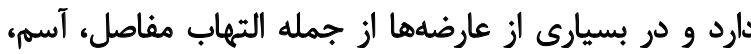

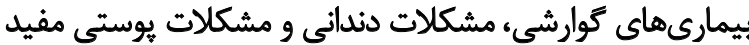

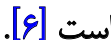

آلوئهورا اجزاي مختلفى دارد كه هركدام از آنها اثرات

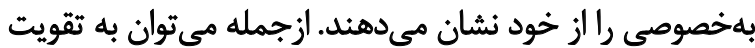

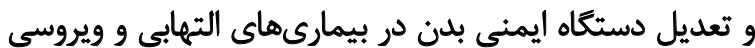

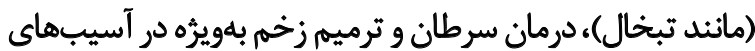

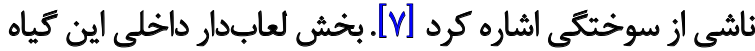

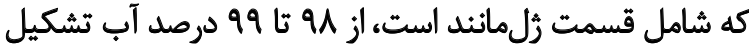

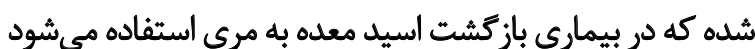

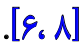

مابقى شامل تركيبات فعالى ازجمله امودين، آلوئزين، آلو آلو إمورين

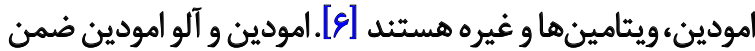

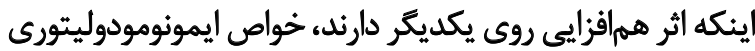

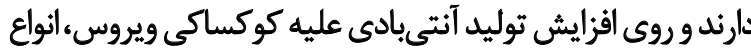

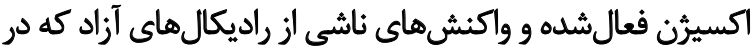

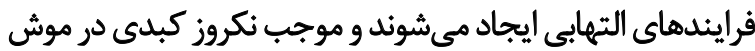

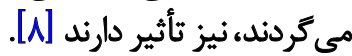

مطالعات بافتشناسى در موشهاى درمانشده با آلو امودين

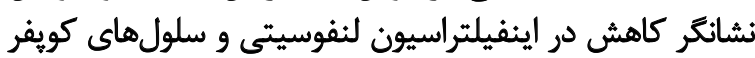

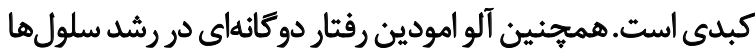

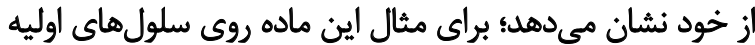

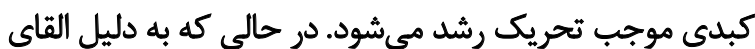

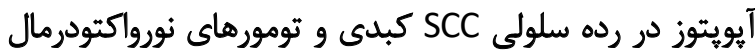

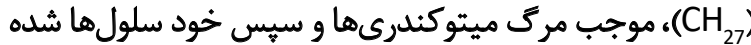

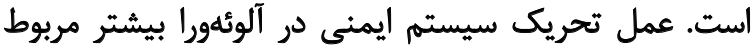

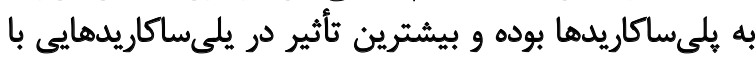

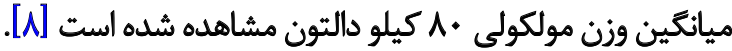

خاصيث آني كه از آلوئهورا استخراج ميشود،

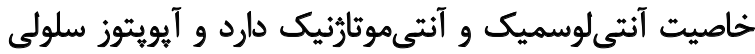

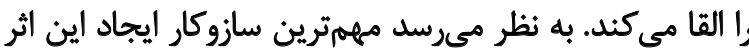

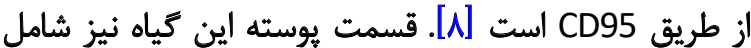
تركيباتى ازجمله -alkaloids، triterpenes، cyanidine، pro 


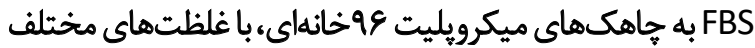
AVL

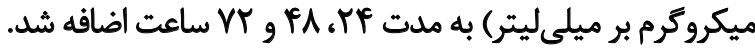

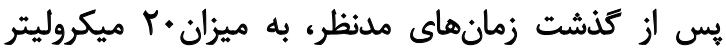

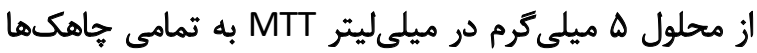

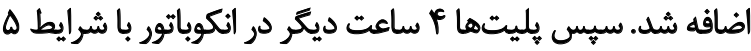

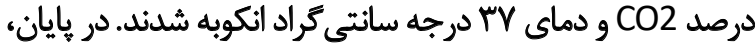

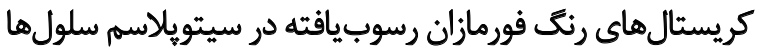

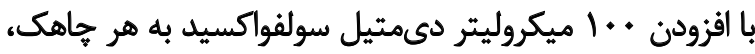

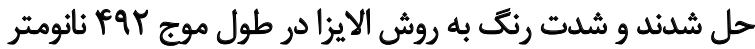

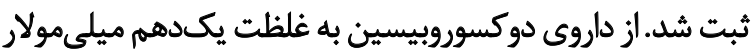

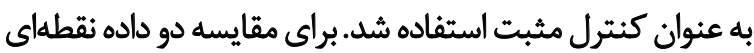

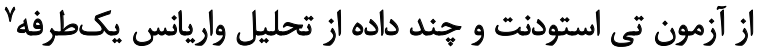
استفاده شد.

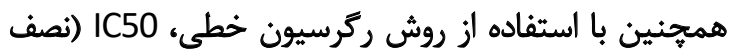

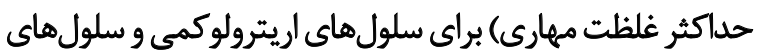

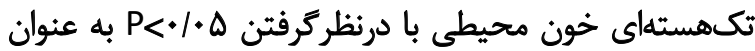
سطح معنى دار در تمامى آزمونها محاسبه شدرئ

Lavill

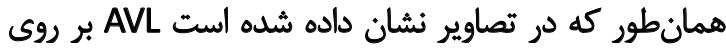

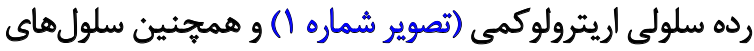

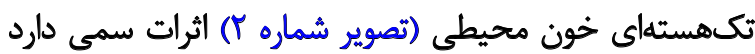

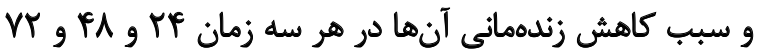

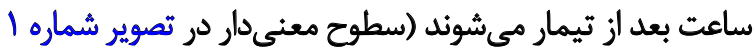

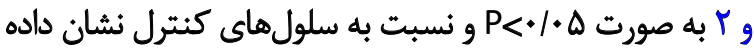

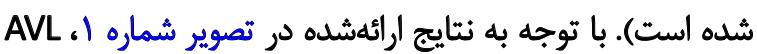

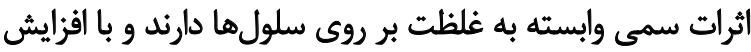

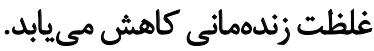

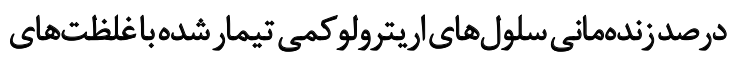

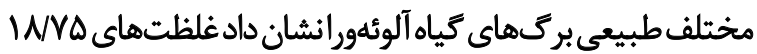

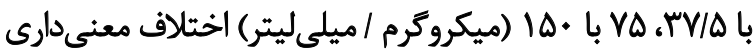

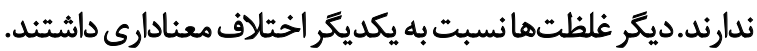

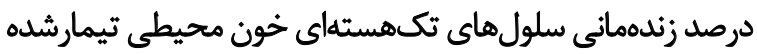

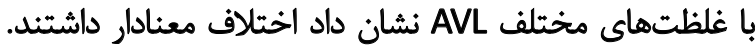

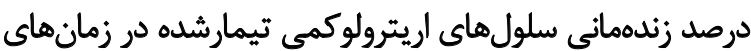

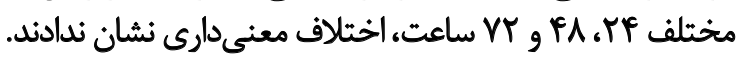

درصد زندهمانى بين سلولهاى اريترولوكمى و سلولهاي

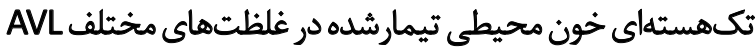

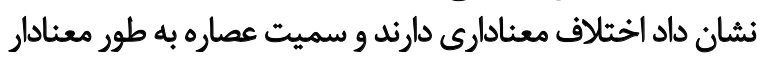

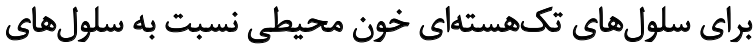

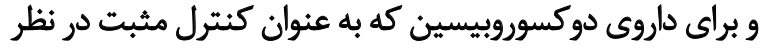

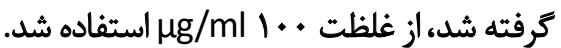

\section{كشت سلول هاي سر طاني اريترولوكمي}

سلولهاى سرطانى اريترولوكمى از بانك سلولى انستيتو ياستور

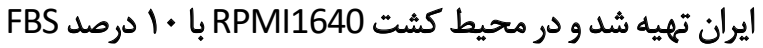

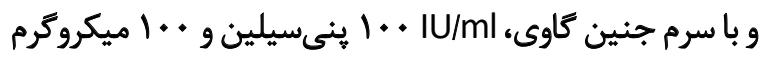

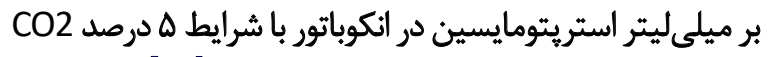

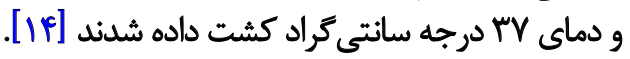

\section{جداسازى سلولهاى تكهستهاى خون محيطى}

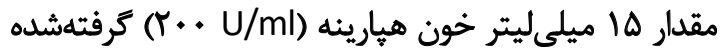

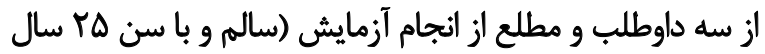

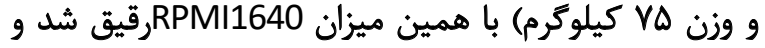

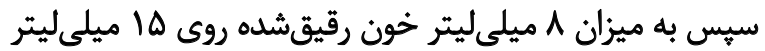

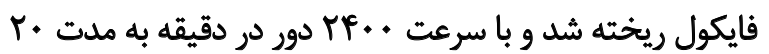

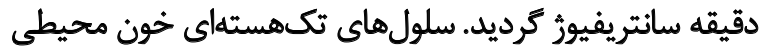

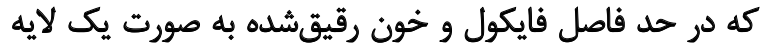

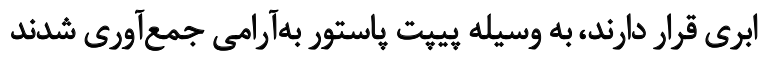

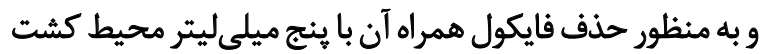

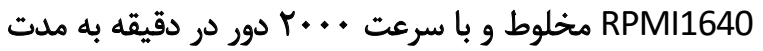
• إقيقه سانتريفيور كرديد.

درنهايت سلولهاى بهدستآمده به منظورحذف بإكتها

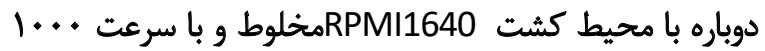

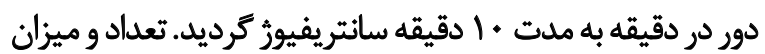

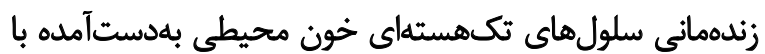

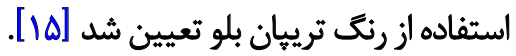

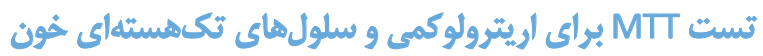

محيطى

از روش MTT براى اندازهيرى ميزان زندهمانى سلولهاي ماني

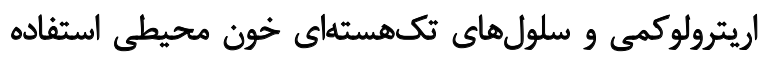

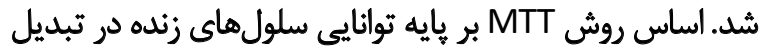

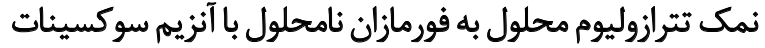

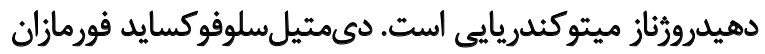

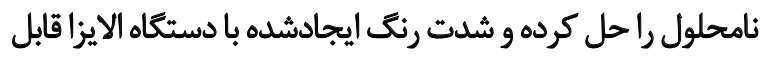

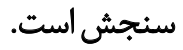

به طور خلاصه، ابتدا سلولهاي اريترولوكمى سانتريفيوز

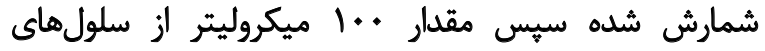

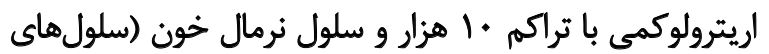

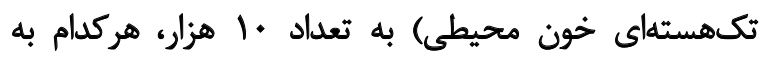

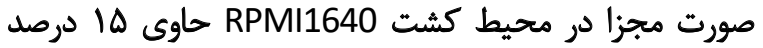


K562-AVL-24,48 and 72h

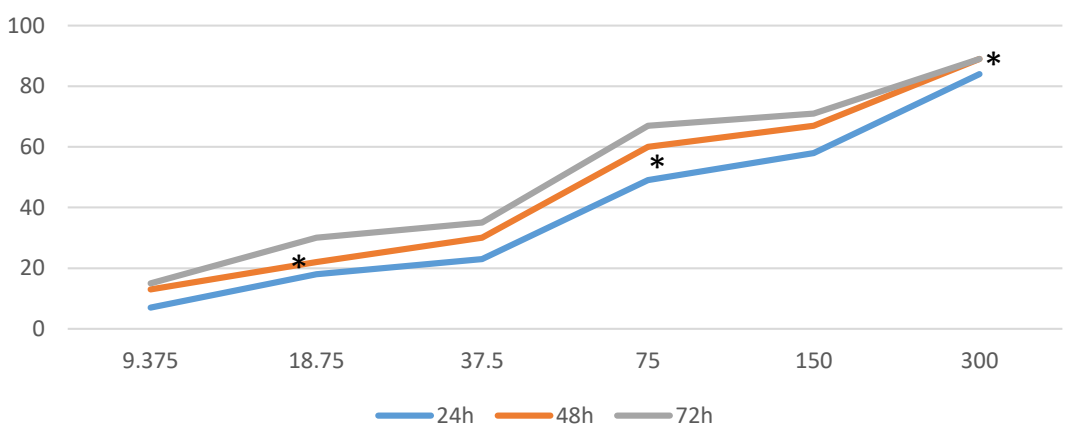

إقتوراتث

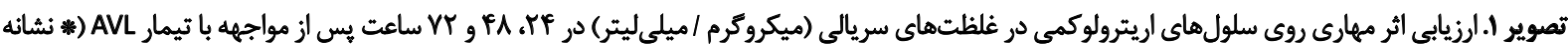

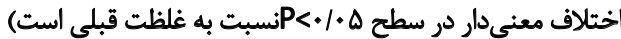

جزء سلول هاى سرطانى خون بامنشأ ميلوئيدى واز رده سلولهاي

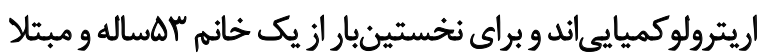
به لوسمى مزمن مغز استخوان جداسازي شدانداندي

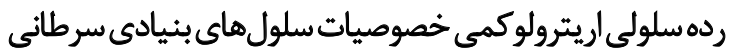

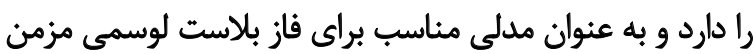

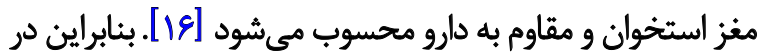

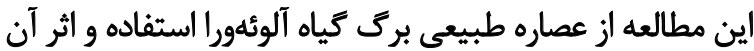
روى سلولهاي اريترولوكمى ارزيابى شد.

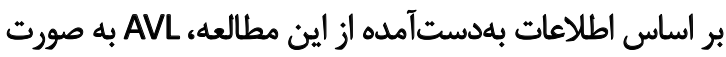

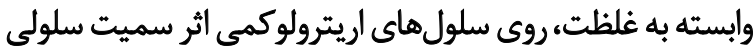

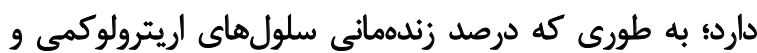

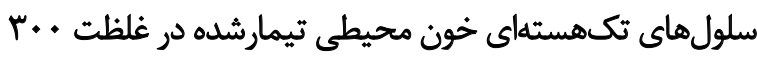

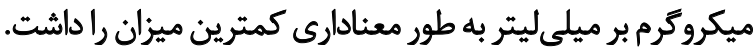

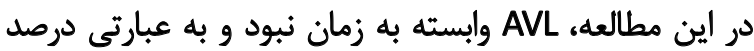

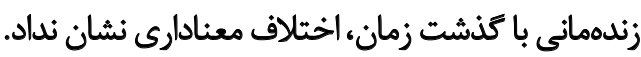

$$
\text { اريترولوكمى بيشتر است. }
$$

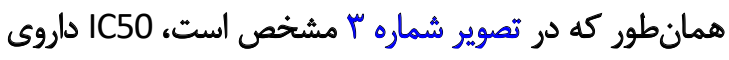

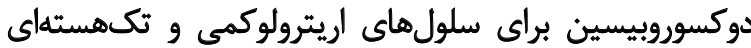

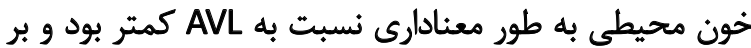

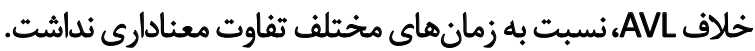

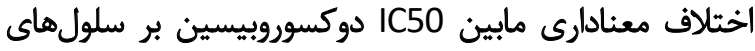

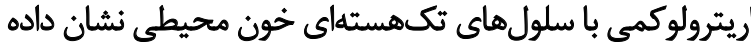

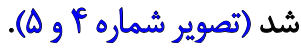

\section{ثિ}

امروزه مطالعات مختلفى در زمينه تأثير عصارههاى كياهى بر

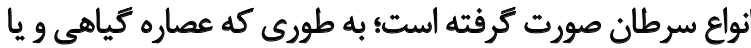

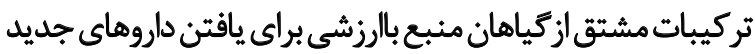

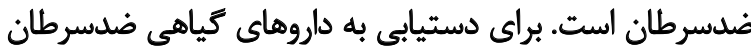

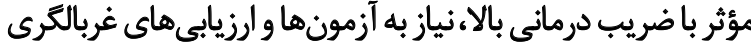

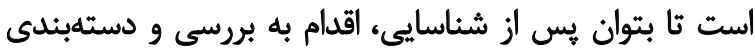

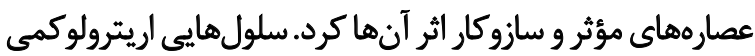

K562-AVL-24,48 and 72h

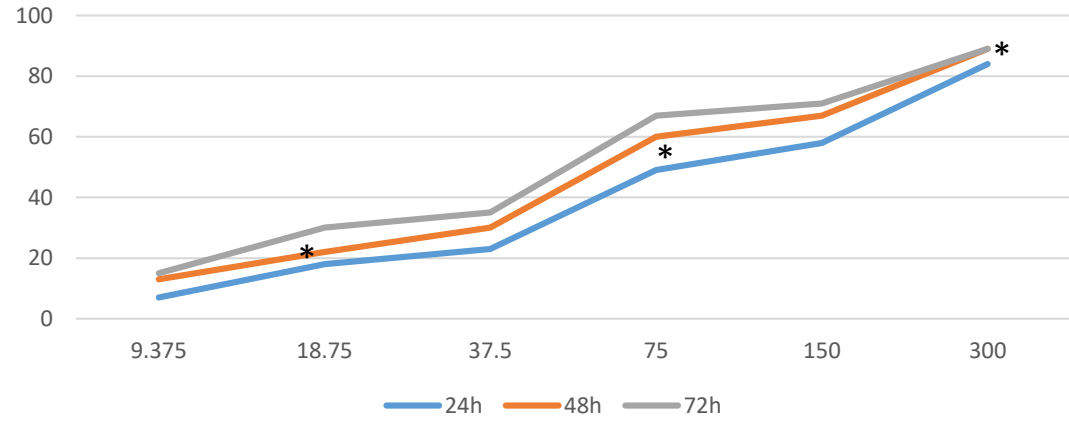

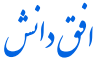

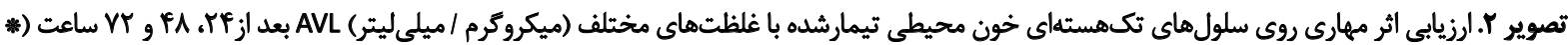

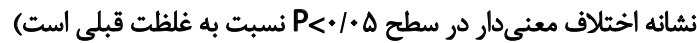




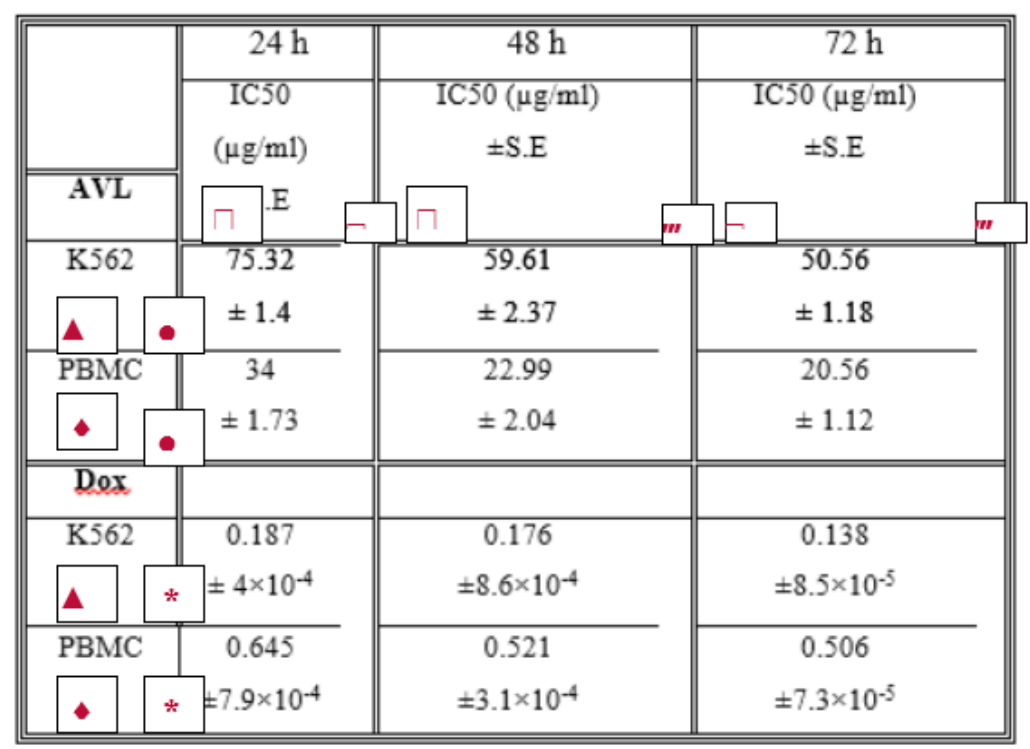

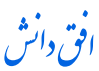

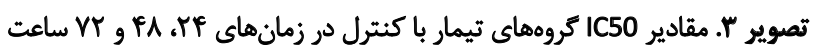

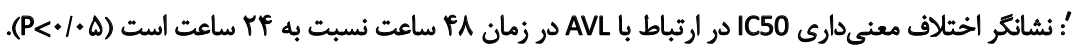

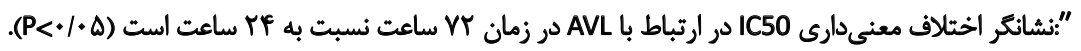

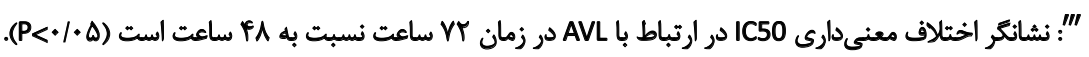

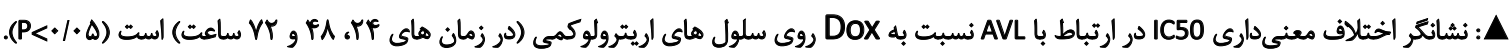

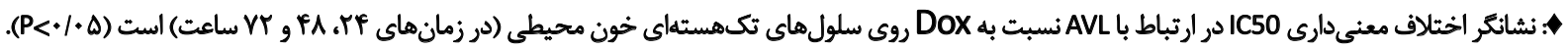

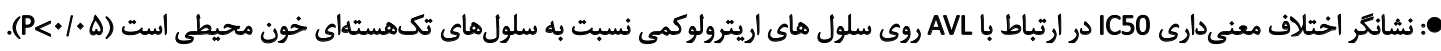

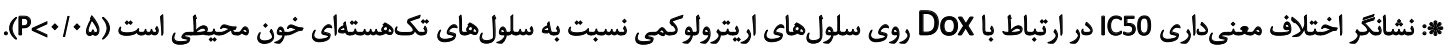

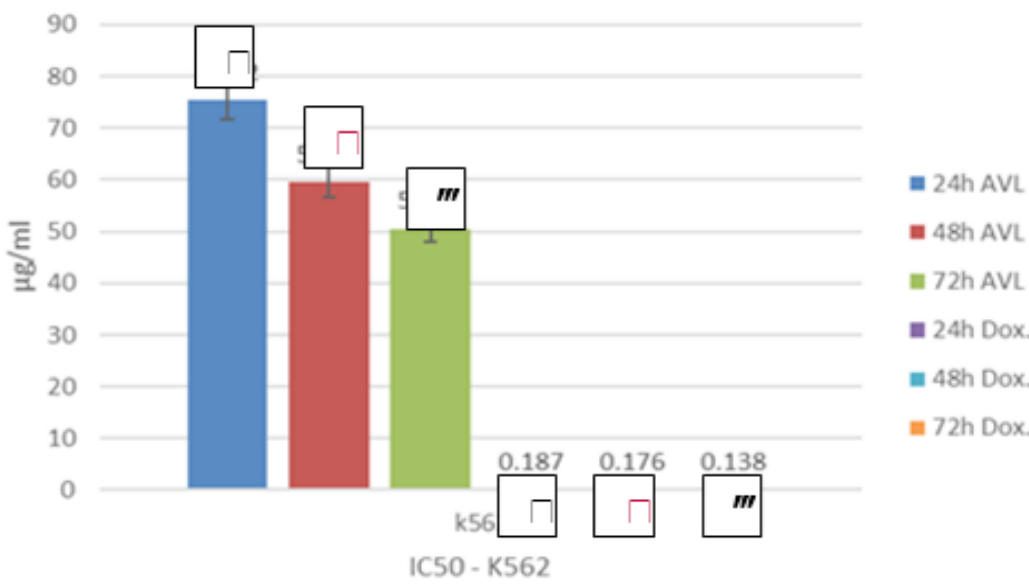

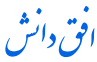

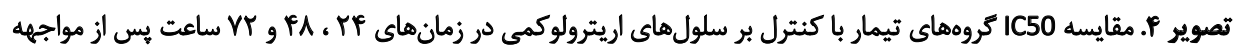

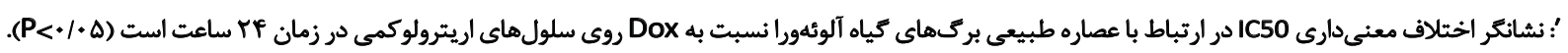

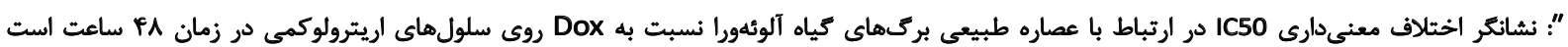
. $(\mathrm{P}<+1 \cdot \Delta)$ "ا." نشانكر اختلاف معنى دارى IC50 در ارتباط با عصاره طبيعى بركهاى كياه آلوئهورا نسبت به Dox روى سلولهاى اريترولوكمى در زمان Vr ساعت است 


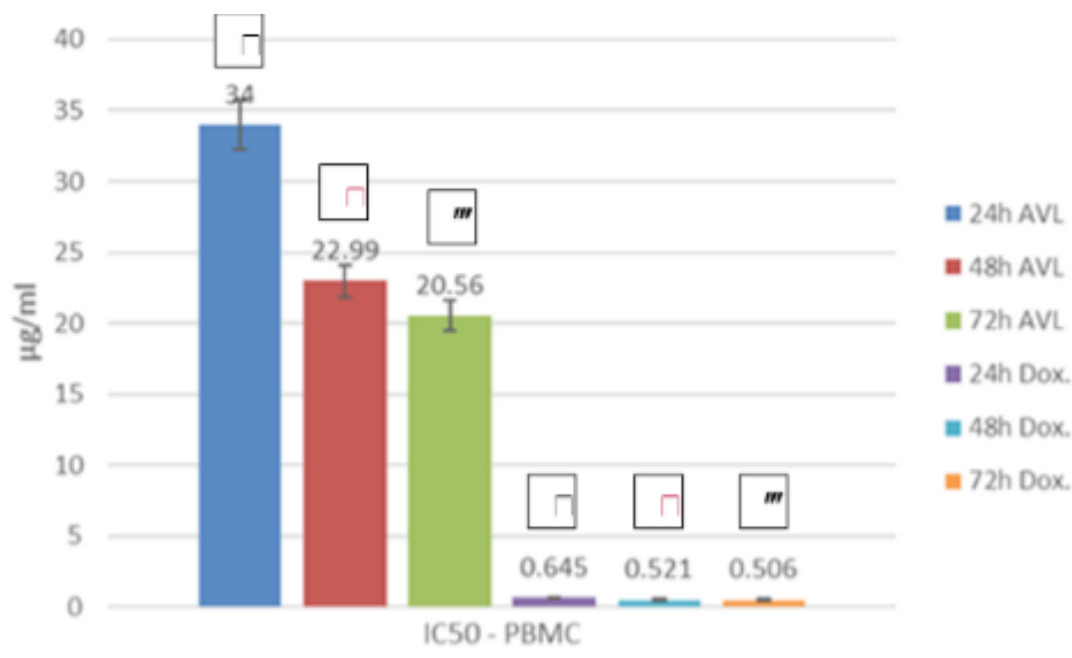

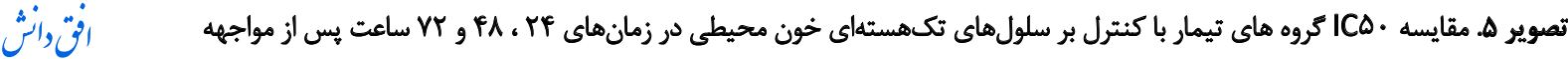

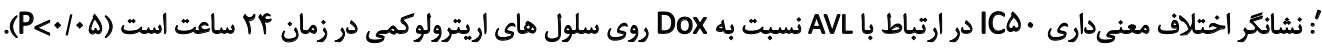

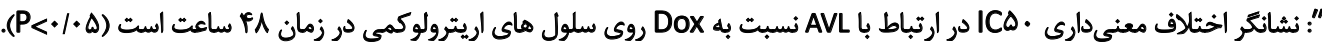

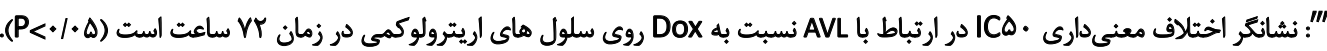

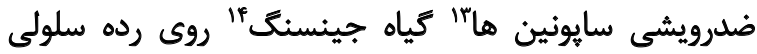

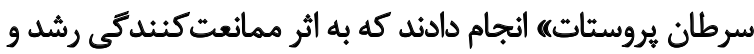

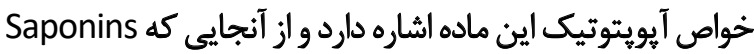

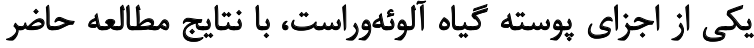
همخواني دارد [19]. در سال •191، وينترز و همكارانش درباره اثر ضدتومورى

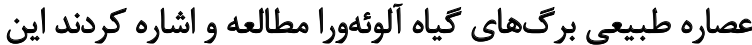

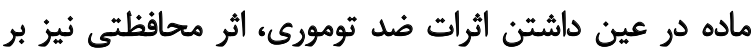

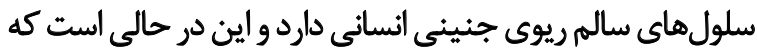

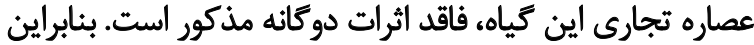

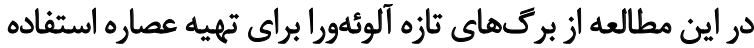

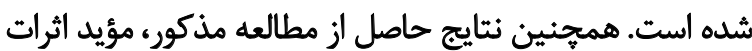

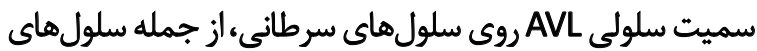
اريترولوكمى است كه با نتايج مطالعه حاضر همخوائى دارد [. [1].

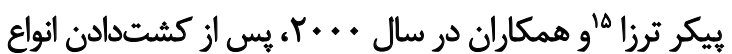

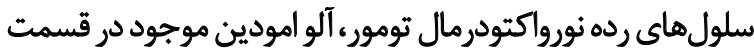

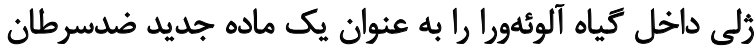
با فعاليت انتخابي عليه تومور نورواكتودرمال، اعلام كردند. آلو آلو

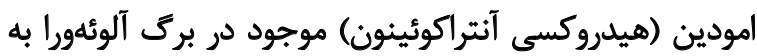

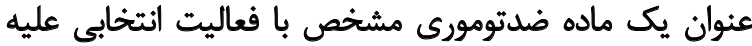

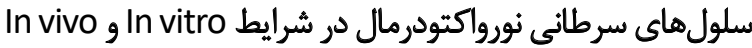

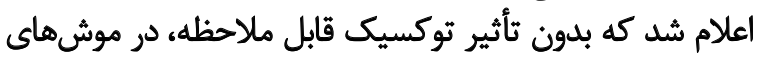

13. Saponins

14. Ginseng

15. Pecere Teresa

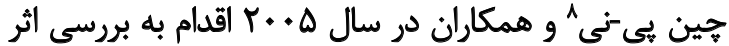

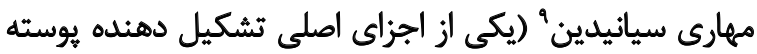

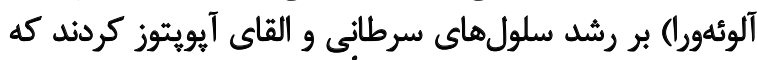

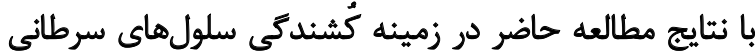

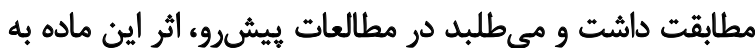

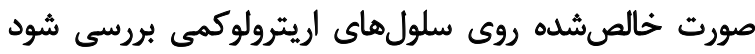

.[IV]

در مطالعه ديكرى كه خي -تاى يائ" و همكاران در سال

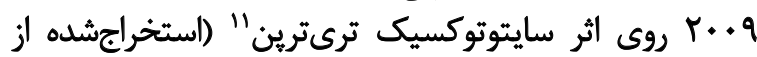

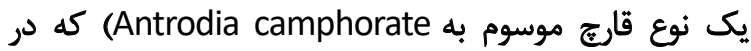

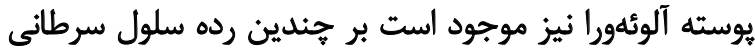

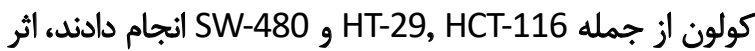

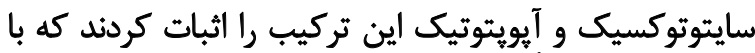

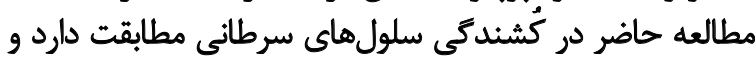

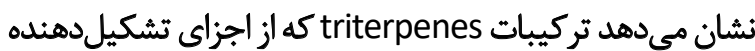

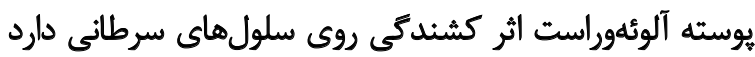

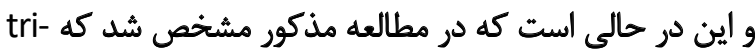
terpenes روى رده سلولهاي إيتليال يستان (MCF10A) و

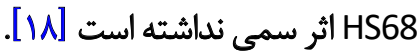

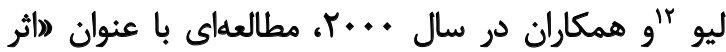

8. ChenPei-Ni

9. Cyanidin

10. Chi-Tai Yeh

11. Triterpenes

12. Liu 
بين مطالعات مختلف تفاوت وجود دارد كه اين امر به عنوان يك متغير تأثيركذار بايد مدنظر قرار كيرد.

$$
\text { تيجئيرى }
$$

با توجه به نتايج تحقيق حاضر، AVL اثر كُشـندكى روى هر دو دو

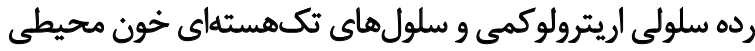

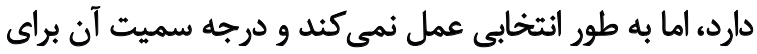

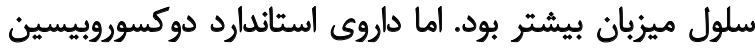

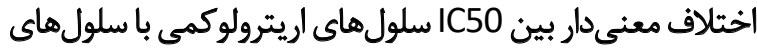

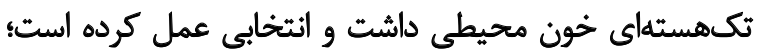

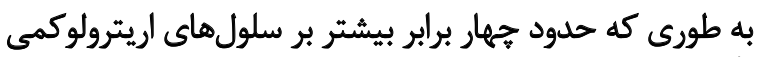
ثأثير داشت.

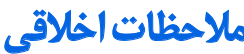

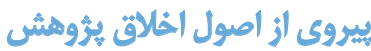

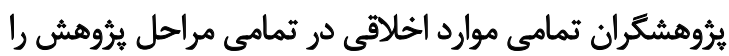

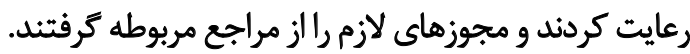

$$
\text { كامي مالى }
$$

منابع مالى اين يرورةه را دانشعاه علوم يزشكى ارتش ثأمين

$$
\text { كرده است. }
$$

\section{مشاركت نويسئد مكان}

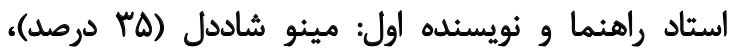

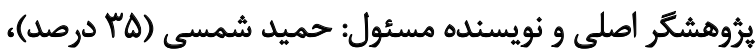

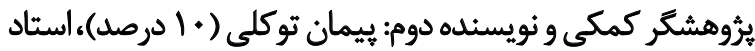

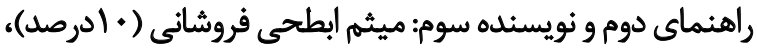

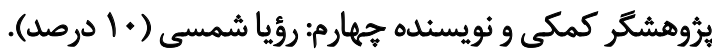

$$
\text { تمارض منأح }
$$

نويسندكان اين مقاله اعلام مى دارند هيج كونه تعارض منافعى در رابطه با اين يُروهش وجود ندارد.
مبتلا به نقص ايمنى مركب حاد موجب كاهش رشد سلولهاي

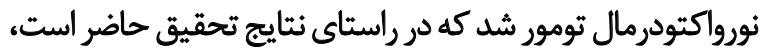

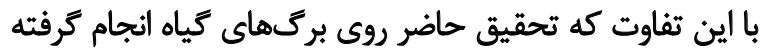

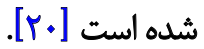

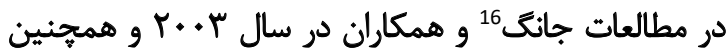

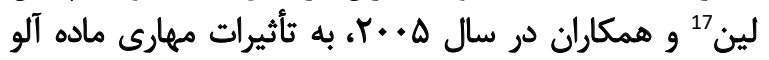

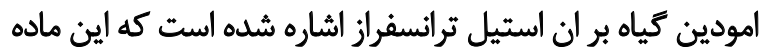

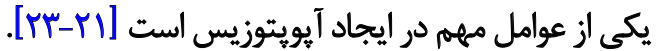

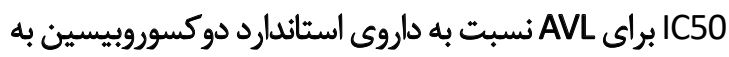

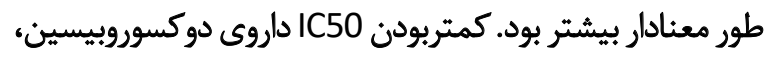

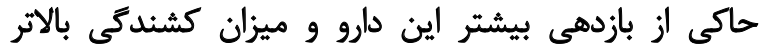

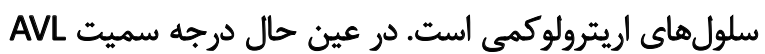

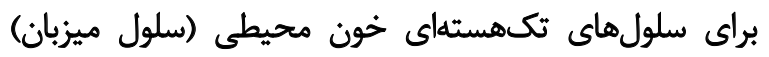

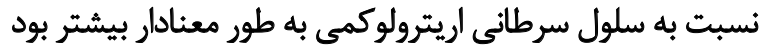

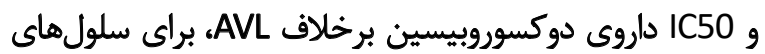

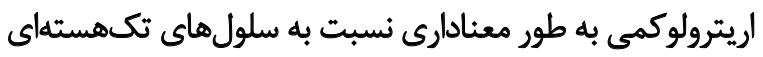

$$
\text { خون محيطى كمتر بود. }
$$

نكته بالهميت اين است كه داروى دوكسوروبيسين به حالت

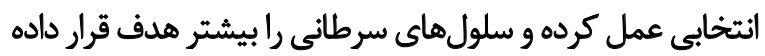

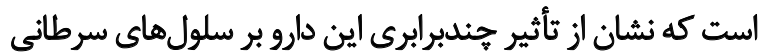

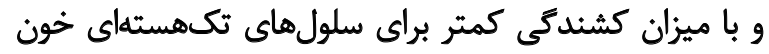

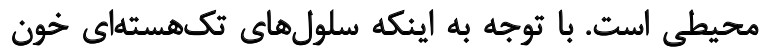

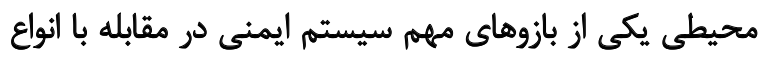

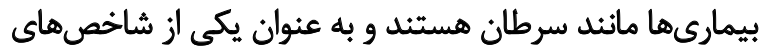

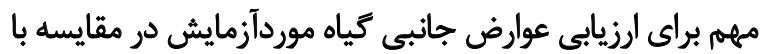

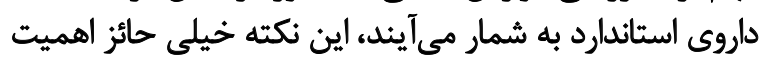

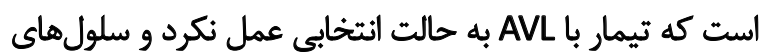

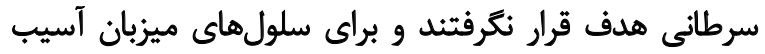
بيشترى همراه داشت.

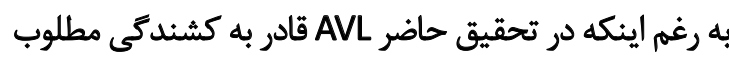

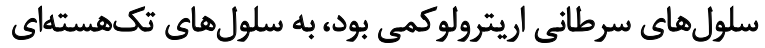

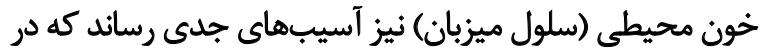

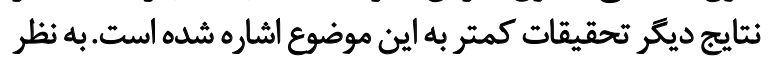

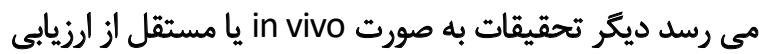

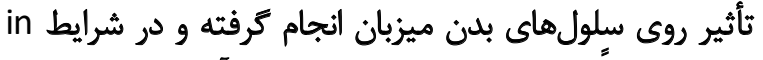

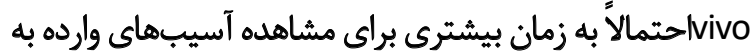

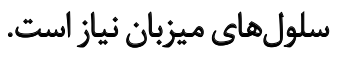

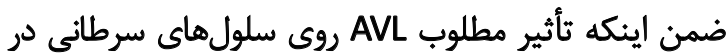

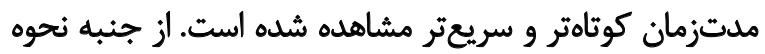

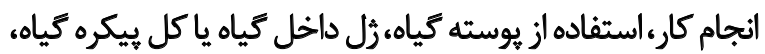




\section{References}

[1] Siegel R, Ward E, Brawley O, Jemal A. The impact of eliminating socioeconomic and racial disparities on premature cancer deaths. Ca-a Cancer Journal for Clinicians. 2011; 61(4):212-36. [DOI:10.3322/caac.20121] [PMID]

[2] Beger RD. A review of applications of metabolomics in cancer. Metabolites. 2013; 3(3):552-74. [DOI:10.3390/metabo3030552] [PMID] [PMCID]

[3] Hengartner MO. The biochemistry of apoptosis. Nature. 2000; 407(6805):770-6. [DOI:10.1038/35037710] [PMID]

[4] Abbas AK, Lichtman AH, Pillai S. IgE-dependent immune responses and allergic disease. Philadelphia: Elsevier-Saunders; 2012.

[5] DeVita Jr VT, Rosenberg SA. Two hundred years of cancer research. New England Journal of Medicine. 2012; 366(23):2207-14. [DOI:10.1056/NEJMra1204479] [PMID] [PMCID]

[6] Fani M, Kohanteb J. Inhibitory activity of Aloe vera gel on some clinically isolated cariogenic and periodontopathic bacteria. Journal of Oral Science. 2012; 54(1):15-21. [DOI:10.2334/josnusd.54.15] [PMID]

[7] Choi SW, Son BW, Son YS, Park YI, Lee SK, Chung MH. The wound-healing effect of a glycoprotein fraction isolated from aloe vera. British Journal of Dermatology. 2001; 145(4):535-45. [DOI:10.1046/j.13652133.2001.04410.x] [PMID]

[8] Harris CC. Chemical and physical carcinogenesis: Advances and perspectives for the 1990s. Cancer Research. 1991; 51(Suppl. 18):5023s-44s. [PMID]

[9] Dutta A, Sarkar D, Gurib-Fakim A, Mandal C, Chatterjee M. In vitro and in vivo activity of Aloe vera leaf exudate in experimental visceral leishmaniasis. Parasitology Research. 2008; 102(6):1235-42. [DOI:10.1007/ s00436-008-0899-2] [PMID]

[10] Winters WD, Benavides R, Clouse WJ. Effects of aloe extracts on human normal and tumor cells in vitro. Economic Botany. 1981; 35(1):8995. [DOI:10.1007/BF02859219]

[11] Lozzio BB, Lozzio CB. Properties and usefulness of the original K-562 human myelogenous leukemia cell line. Leukemia Research. 1979; 3(6):363-70. [DOI:10.1016/0145-2126(79)90033-X]

[12] Dutta A, Mandal G, Mandal C, Chatterjee M. In vitro antileishmanial activity of Aloe vera leaf exudate: A potential herbal therapy in leishmaniasis. Glycoconjugate Journal. 2007; 24(1):81-6. [DOI:10.1007/s10719006-9014-z] [PMID]

[13] Dutta A, Bandyopadhyay S, Mandal C, Chatterjee M. Aloe vera leaf exudate induces a caspase-independent cell death in Leishmania donovani promastigotes. Journal of Medical Microbiology. 2007; 56(5):62936. [DOI:10.1099/jmm.0.47039-0] [PMID]

[14] Kabiri F, Nejati V, Tukmechi A, Delirezh N, Nikbakhsh P. [Inhibitiory properties of cytoplasmic extract of Lactobacilli isolated from common carp intestine on human chronic myelocytic leukemia K562 cell line: An in vitro study (Persian)]. Tehran University Medical Journal. 2011; 68(12):691-8.

[15] Coligan JE, Bierer BE, Margulies DH, Shevach EM, Strober W. Preface- current protocols in immunology. Wiley. 2010; 89(1):iii-vi. [DOI:10.1002/0471142735.imprefs89] [PMID] [PMCID]

[16] Andersson LC, Nilsson K, Gahmberg CG. K562-a human erythroleukemic cell line. International Journal of Cancer. 1979; 23(2):143-7. [DOI:10.1002/ijc.2910230202] [PMID]
[17] Chen PN, Chu SC, Chiou HL, Chiang CL, Yang SF, Hsieh YS. Cyanidin 3-glucoside and peonidin 3-glucoside inhibit tumor cell growth and induce apoptosis in vitro and suppress tumor growth in vivo. Nutrition and Cancer. 2005; 53(2):232-43. [DOI:10.1207/s15327914nc5302_12] [PMID]

[18] Yeh CT, Rao YK, Yao CJ, Yeh CF, Li CH, Chuang SE, et al. Cytotoxic triterpenes from Antrodia camphorata and their mode of action in HT-29 human colon cancer cells. Cancer Letters. 2009; 285(1):73-9. [DOI:10.1016/j.canlet.2009.05.002] [PMID]

[19] Liu WK, Xu SX, Che CT. Anti-proliferative effect of ginseng saponins on human prostate cancer cell line. Life Sciences. 2000; 67(11):1297-306. [DOI:10.1016/S0024-3205(00)00720-7]

[20] Pecere T, Gazzola MV, Mucignat C, Parolin C, Dalla Vecchia F, Cavaggioni $A$, et al. Aloe-emodin is a new type of anticancer agent with selective activity against neuroectodermal tumors. Cancer Research. 2000 60(11):2800-4. [PMID]

[21] Chung JG, Li YC, Lee YM, Lin JP, Cheng KC, Chang WC. Aloe-emodin inhibited $\mathrm{N}$-acetylation and DNA adduct of 2-aminofluorene and $\mathrm{Ar}$ ylamine $\mathrm{N}$-acetyltransferase gene expression in mouse leukemia L 1210 cells. Leukemia Research. 2003; 27(9):831-40. [DOI:10.1016/S0145 2126(03)00017-1]

[22] Lin SY, Yang JH, Hsia TC, Lee JH, Chiu TH, Wei YH, et al. Effect of inhibition of aloe-emodin on $\mathrm{N}$-acetyltransferase activity and gene expression in human malignant melanoma cells (A375. S2). Melanoma Research. 2005; 15(6):489-94. [DOI:10.1097/00008390-200512000-00002] [PMID]

[23] Liu K, Liu Y, Yu Y, Feng T, Zhang S. Identification of acetylcholine-related enzymes and the role of acetylcholine and nicotine in human cervical cancer. International Journal of Clinical and Experimental Pathology. 2016; 9(4):4854-61 
This Page Intentionally Left Blank 